\title{
Enginar Yaprağı Sulu Ekstraktı Kullanılarak Çinko Oksit Nanopartiküllerinin Yeşil Sentezi, Karakterizasyonu, Anti-Bakteriyel ve Sitotoksik Etkileri
}

\author{
Green Synthesis, Characterization, Anti-bacterial and Cytotoxic Effects of Zinc Oxide \\ Nanoparticles Using Aqueous Extract of Artichoke Leafs
}

\author{
Ömer ERDOĞAN ${ }^{1}$ \\ (i) 0000-0002-8327-7077 \\ Fatih BİRTEKOCAK ${ }^{1}$ \\ (1) 0000-0003-1212-8346 \\ Erman ORYASSIN ${ }^{2}$ \\ (1) 0000-0003-1242-7434 \\ Mürüvvet ABBAK ${ }^{2}$ \\ (i) 0000-0001-7743-6265 \\ Gülen Melike DEMIRBOLAT ${ }^{3}$ \\ (D) 0000-0001-5621-5818 \\ Salih PASA ${ }^{4}$ \\ (1) 0000-0002-4792-8821 \\ Özge ÇEVİK ${ }^{1}$ \\ (1) 0000-0002-9325-3757
}

\section{${ }^{1}$ Adnan Menderes Üniversitesi Tip Fakültesi Biyokimya AD, Aydın \\ ${ }^{2}$ Adnan Menderes Üniversitesi Bilim ve Teknoloji Araştırma Uygulama Merkezi, Aydın \\ ${ }^{3}$ Cumhuriyet Üniversitesi Eczacilık Fakültesi Farmasötik Teknoloji AD, Sivas \\ ${ }^{4}$ Afyon Kocatepe Üniversitesi Eğitim Fakültesi Fen Bilimleri Eğitimi AD, Afyon}

\section{Sorumlu Yazar \\ Corresponding Author \\ Özge ÇEVIK \\ ozge.cevik@adu.edu.tr}

Geliş Tarihi / Received : 13.11.2018 Kabul Tarihi / Accepted : 25.02.2019 Çevrimiçi Yayın Tarihi /

Available Online

\section{öz}

Amaç: Bu çalışmanın amacı, yeşil kimya yöntemiyle çinko oksit nanopartiküllerini (ZnONPs) sentezlemek ve bu nanopartiküllerin anti-bakteriyel ve anti-kanser etkilerini incelemektir.

Gereç ve Yöntemler: Çinko iyonları ve sulu enginar yaprağı (Cynara scolymus) ekstraktı kullanılarak ZnONPs yeșil kimya yöntemiyle sentezlendi. ZnONPs olușumunun doğrulanması ve karakterizasyonu için morötesi-görünür bölge spektroskopisi (UV-Vis), Fourier dönüşümü kızılötesi spektroskopisi (FTIR), taramalı elektron mikroskobu (SEM), zetasizer ve Enerji dağınım X-ışını spektroskopisi (EDX) analizleri kullanıldı. ZnONPs'nin 4 farklı bakteri türü ( $E$. coli, $S$. aureus, $P$. aeruginosa ve $E$. faecalis) üzerindeki antibakteriyel aktiviteleri, minimal inhibe edici konsantrasyon (MİK) ve kuyucuk difüzyon yöntemiyle ölçüldü. ZnONPs'nin HT-29 insan kolon kanseri hücreleri üzerindeki sitotoksik etkileri konsantrasyon ve zamana bağll olarak olarak belirlendi.

Bulgular: UV-Vis spektrumunda ZnO'ya spesifik olan 320-335 nm aralığında absorbans artışı gözlemlendi. FTIR spektrumunda $426 \mathrm{~cm}^{-1}$ ve $540 \mathrm{~cm}^{-1}$ 'de ZnO'ya ait gerilme titreşimleri belirlendi. SEM analizinde partikül boyutu 276-309 nm ölçüldü. ZnONPs'nin zeta-sizer analizlerinde partikül büyüklügü $137,8 \mathrm{~nm}$ ve partikül yükü $-6,34 \mathrm{meV}$ olarak bulundu. Antibakteriyel aktivite ölçümlerinde, sentezlenen nanopartiküllerin $E$. coli ve $S$. aureus'ta bakteriyel aktivite inhibisyonu sağladığı tespit edildi. ZnONPs HT-29 kolon kanseri hücreleri üzerinde $10 \mu \mathrm{g} / \mathrm{mL}$ 'den daha yüksek konsantrasyonlarda sitotoksik etki gösterdi.

Sonuç: ZnONPs'nin düşük maliyetle hazırlanabileceği ve klinik tedavilerde yeni ilaç formülasyonları için taşıyıcı sistem olarak kullanılma potansiyeline sahip olduğu bu çalışma ile gösterilmiştir.

Anahtar kelimeler: Çinko oksit nanopartikül; yeşil kimya; anti-bakteriyel; sitotoksisite; kolon kanseri.

\section{ABSTRACT}

Aim: The aim of this study is to synthesize zinc oxide nanoparticles (ZnONPs) by green chemistry method and investigate anti-bacterial and anticancer effects of these nanoparticles. Material and Methods: ZnONPs were synthesized by the green chemistry method using zinc ions and aqueous artichoke leaf (Cynara scolymus) extract. Ultraviolet-visible spectroscopy (UV-Vis), Fourier-transform infrared spectroscopy (FTIR), scanning electron microscope (SEM), zetasizer and energy dispersive X-ray spectroscopy (EDX) were used to confirm the formation and characterization of ZnONPs. Antibacterial activities of ZnONPs on four different bacteria species (E. coli, S. aureus, P. aeruginosa and E. faecalis) were measured by minimal inhibitory concentration (MIC) and agar well diffusion method. Cytotoxic effects of ZnONPs on HT-29 human colon cancer cells were determined as concentration and time dependent.

Results: In the UV-Vis spectrum, absorbance increase was observed in $320-335 \mathrm{~nm}$ range which is specific to $\mathrm{ZnO}$. In the FTIR spectrum, stretching vibrations of $\mathrm{ZnO}$ were determined in $426 \mathrm{~cm}^{-1}$ and $540 \mathrm{~cm}^{-1}$. The particle size was 276-309 nm in SEM analysis. In the zeta-sizer measurements of ZnONPs, the particle size was $137.8 \mathrm{~nm}$ and the particle charge was -6.34 $\mathrm{meV}$. In the antibacterial activity measurements, it was determined that synthesized nanoparticles induce inhibition of bacterial activity in E. coli and S. aureus. ZnONPs showed cytotoxic effects on HT-29 cells at concentrations higher than $10 \mu \mathrm{g} / \mathrm{mL}$.

Conclusion: This study showed that $\mathrm{ZnONPs}$ can be prepared at low cost and have potential to be used as a carrier system for new drug formulations in clinical therapies.

Keywords: Zinc oxide nanoparticle; green chemistry; anti-bacterial; cytotoxicity; colon cancer. 


\section{GíRIŞ}

Nanoteknoloji 1-100 nm boyutlarında materyaller geliştirmeyi amaçlayan, son y1llarda önemi gittikçe artan bir bilim dalıdır. Nanopartiküller sağlık, gıda, uzay, farmasötik ve kozmetik endüstrilerinde geniş kullanım alanı bulmaktadırlar. Nano skalada endüstriyel üretimin gelişmesi ile gümüş oksit $(\mathrm{AgO})$, altın oksit $(\mathrm{AuO})$, titanyum dioksit $\left(\mathrm{TiO}_{2}\right)$, bakır oksit $(\mathrm{CuO})$, seryum oksit $\left(\mathrm{CeO}_{2}\right)$ gibi metal oksitleri geniş pazar alanı bulmuşlardır. Çinko oksit $(\mathrm{ZnO})$ nano yapıları sahip oldukları optik ve elektriksel özelliklerinden dolayı araştırmacıların gözde çalışma konularından biridir (1-4). Nanopartiküllerin biyolojik sistemlerde nasıl ve hangi amaçla kullanılması gerektiği ile ilgili literatürde belirgin bir alan bulunmamaktadır. Birçok alanda kullanılan nanopartiküller için sentezlendikten sonra çeşitli aktivite çalışmaları yapılmaktadır. Çinko oksit nanopartiküllerinin (ZnONPs), çeşitli bakteri suşlarının büyümesini inhibe ettiği ve çeşitli kanser hücre hatlarına karşı da sitotoksik etki gösterdiği bilinmektedir (5-7). ZnONPs mükemmel ilaç taşıyıcı sistemler olarak tanımlanmaktadırlar. ABD Gıda ve İlaç İdaresi (FDA) partikül boyutu 100 nm'den daha büyük olan ZnONPs'nin ilaç dağıtım sistemi olarak kullanımlarını desteklemekte ve bu partiküllerin biyouyumlu olduğunu bildirmektedir (6). ZnO diğer metaloksit nanopartikülleri ile karşılaştırıldığında nispeten ucuz, biyouyumlu ve daha az toksik olduğu için daha geniş uygulama potansiyeline sahip olduğu yapılan araştırmalar ile desteklenmiştir $(8,9)$. Buna ek olarak farmasötik olarak aktif moleküllerin çoğunluğu ile ZnONPs'nin etkileşime girmediği de gösterilmiştir (10).

Nanopartiküller için fiziksel, kimyasal ve yeşil sentez olmak üzere üç farklı sentez yöntemi geliştirilmiştir. Fiziksel metotlar ile nanopartikül sentezinde pahalı ekipmanlar, yüksek sıcaklık ve yüksek basınç gerekmektedir. Kimyasal metotlar ile nanopartikül sentezinde ise çevreye ve canlılara ciddi zararlar verebilecek toksik kimyasallar kullanılmaktadır (11). Fiziksel ve kimyasal sentezin dezavantajlarından dolayı bu metotların yerini çevre-canlı dostu ve daha ucuz bir yöntem olan yeşil sentez (green synthesis) almıştır. Nanopartiküllerin yeşil sentezi için bitkiler, bakteriler, mantarlar, algler gibi çeşitli doğal moleküller içeren biyolojik kaynaklar kullanılmaktadır (12-15).

Enginar (Cynara scolymus) ülkemizde Akdeniz ve Ege bölgesinde yetişen çok y1llk bir bitkidir. Enginar ekstraktının içerdiği biyobileşenlerin anti-oksidan, anti-inflamatuvar, anti-alerjik, anti-ülserojenik, anti-hepatoselüler karsinom aktivite gösterdiği bilinmektedir (16-18). Enginar ekstraktının klorojenik asit, luteolin, kafeik asit türevleri, flavanoidler gibi metabolitlerce zengin bir içeriğe sahip olduğu bildirilmiştir (19-23). Enginar kullanılarak, metal oksitlerden nanopartiküllerin yeşil kimya yoluyla sentezi konusunda literatürde kısıtlı sayıda çalışma bulunmaktadır (24). İçeriğinde bulunan biyoaktif bileşenlerin nanopartikül sentezini kolaylaştırması ve zararsız etkileri sebebiyle bu alanda yapılan çalışmalar son yıllarda artış göstermektedir. $\mathrm{Bu}$ çalışmada enginar yaprağı ekstraktı kullanılarak ZnONPs'nin yeşil kimya yoluyla sentezi gerçekleştirilmiştir. Sentezlenen nanopartiküllerin karakterizasyon çalışmaları morötesi-görünür bölge spektroskopisi (UV-Vis), Fourier dönüşümü kızılötesi spektroskopisi (FTIR), taramalı elektron mikroskobu (SEM), zeta sizer ve enerji dağınım X-1şını spektroskopisi (EDX) kullanılarak yapılmıştır. Sentezlenen nanopartiküllerin E. coli, S. aureus, E. faecalis ve $P$. aeruginosa üzerindeki anti-bakteriyel etkileri ve HT-29 kolon kanser hücreleri üzerinde anti-kanser etkileri incelenmiştir.

\section{GEREÇ VE YÖNTEMLER \\ Enginar Ekstraktının Hazırlanması}

Enginarlar Aydın yerel halk pazarından satın alındı. Enginar yaprakları Rao ve ark. (25) tarafindan önerilen yönteme göre ekstrakte edildi. Enginarın yaprak kısmı alınarak $3 \mathrm{kez}$ deiyonize su ile yıkandı. Yapraklar mutfak robotundan geçirilerek küçük parçalara ayrılması sağlandı. Bir litre erlenmayer içerisine 200 g enginar yaprağ 1 ve 400 $\mathrm{mL}$ deiyonize su eklendi. Bu karışım manyetik ısıtıcıda $100^{\circ} \mathrm{C}$ 'de 2 saat boyunca 1sıttld1. Elde edilen karışım Whatman (Grade GF/B: 1,0 $\mu \mathrm{m}$ ) filtre kağıdından süzülerek ekstrakt elde edildi ve sentez aşamasında taze hazırlanarak kullanıldı.

\section{Çinko Oksit Nanopartiküllerinin Sentezi}

ZnONPs, Siby ve Beena (26) ve Haris ve ark. (27) tarafından önerilen yöntemler modifiye edilerek sentezlendi. Bunun için, $100 \mathrm{~mL}$ 'lik bir behere $20 \mathrm{~mL}$ çinko sülfat $\left(\mathrm{ZnSO}_{4}\right)$ çözeltisi $(10 \mathrm{mM})$ eklendi. Bu karışımın üzerine $20 \mathrm{~mL}$ enginar ekstraktı damla damla ilave edildi. 30 dakika boyunca ultrasonik banyoda (Bandelin, USA) karıştırıldı. $360 \mathrm{~W}$ mikrodalga fırında (Arçelik MD-674, Türkiye) 5 dakika bekletildi. Karışım falkon tüplere alınarak 4000 rpm'de 10 dakika boyunca santrifüj (Hettich, USA) edildi. Elde edilen pellet organik kalıntıların uzaklaştırılması için etanol ile 5 kez yıkanıp tekrar santrifüj edildi. Pellet kısmı alınarak $100^{\circ} \mathrm{C}$ 'lik etüvde (Memmert, USA) 12 saat boyunca kurutuldu. Elde edilen nanopartiküller, antimikrobiyal ve sitotoksisite çalışmalarında kullanılmak üzere ependorf tüplerde muhafaza edildi (Şekil 1).

Çinko Oksit Nanopartiküllerinin Karakterizasyonu ZnONPs'nin optik özellikleri, 200-800 nm arasındaki UVVis bölge spektrumları (Thermo Multiscan 1500) alınarak karakterize edildi. Fonksiyonel grup analizi için FTIR (Shimadzu IR 8000) kullanıldı. Partikül şekli ve boyutu SEM (LEO 1430 VP) ile ölçüldü. Sentezlenen nanopartiküllerin elementel bileşimini aydınlatmak için EDX (LEO 1430 VP) kullanıldı. Sentezlenen ZnONPs'nin büyüklük dağılımları ve yüzey yükleri Zetasizer cihazı (Malvern ZS) ile ölçüldü.

Çinko Oksit Nanopartiküllerinin Antimikrobiyal Aktiviteleri

Çalışmada sentezlenen nanopartiküllerin referans bakterilere karşı etkisi agar kuyucuk diffüzyon yöntemi ile belirlendi. Bu amaçla E. coli ATCC 25922, S. aureus ATCC 25923, P. aeruginosa DSM 22644 ve E. faecalis JH2-2 referans bakterileri kullanıldı (28). Çalışmada kullanılan mikroorganizma kültürleri Adnan Menderes Üniversitesi Rekombinant DNA ve Rekombinant Protein Merkezi (REDPROM) kültür koleksiyonundan temin edildi.

\section{Kuyucuk Difüzyon Yöntemi ile Antimikrobiyal Aktivite} Tayini

$0,5 \mathrm{McF}$ arland yoğunluğunda $100 \mu \mathrm{L}$ bakteri süspansiyonu alınarak petrilere yayıldı. $6 \mathrm{~mm}$ punch kullanılarak petrilere 


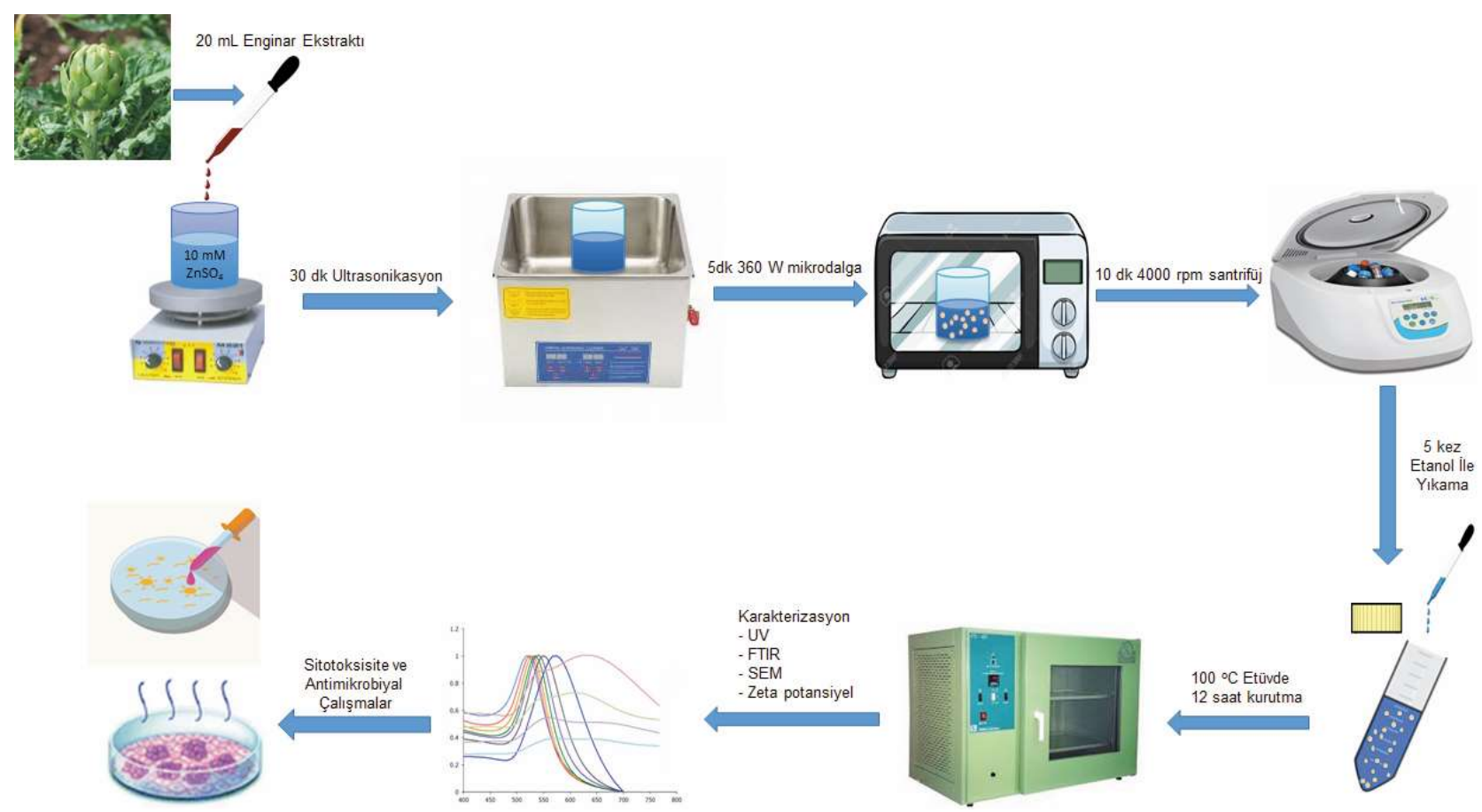

Şekil 1. Sentez basamaklarının şekilsel gösterimi

kuyucuklar açıldı ve açılan kuyucuklara farklı konsantrasyonlarda hazırlanmış olan ZnONPs içeren solüsyonlardan $50 \mu \mathrm{L}$ konuldu. Petriler 16 saat $37^{\circ} \mathrm{C}$ 'de inkübe edildi ve inkübasyon sonrasında oluşan zonların çapları mm olarak ölçüldü. Çalışma üç tekrarlı yapılarak elde edilen sonuçların ortalaması ve standart sapmaları hesaplandı. Negatif kontrol olarak su, pozitif kontrol olarak Ampisilin (Amp) kullanıldı.

Mikrodilüsyon Yöntemi ile Minimal İnhibe Edici Konsantrasyon Testi

96 kuyucuklu U tabanlı well playtler kullanılarak, 0,5 McFarland standardına göre bakteriler elisa platelerine ekildi (29). ZnONPs'nin $128 \mu \mathrm{g} / \mathrm{mL}-0,25 \mu \mathrm{g} / \mathrm{mL}$ aralığında çözeltileri hazırlandı. Hazırlanan bu çözeltilerden $100 \mu \mathrm{L}$ alınarak bakterilerin üzerine eklendi. Her bir dilüsyon serisi için üreme kontrolü ile negatif kontrol kullanıldı. Dilüsyonların hazırlanmasından sonra bakteri inokülasyonları gerçekleştirilerek 16 saat $37^{\circ} \mathrm{C}$ 'de inkübe edildi. İnkübasyon sonrasında tekrar Elisa okuyucusunda absorbansı ölçülen bakterilerin değerleri arasındaki fark karş̧laştırıldı.

\section{Sitotoksisite Testi}

\section{Hücre Külttürü}

Bu çalı̧̧mada Amerikan Tip Kültür Koleksiyonuna ait (ATCC, Manassas, VA, USA) HT-29 insan kolon kanser hücreleri kullanıldı. HT-29 hücreleri \%10 FBS (Sigma F-2442), 2mM L-glutamine (Sigma G-6392), $100 \mathrm{U} / \mathrm{mL}$ penisilin ve $100 \mu \mathrm{g} / \mathrm{mL}$ streptomisin içeren modifiye edilmiş RPMI-1640 hücre kültür medyumu (Gibco11875093 ) içerisinde, $75 \mathrm{~cm}^{2}$ flasklarda, $\% 5 \mathrm{CO}_{2}{ }^{\prime}$ li etüvde (Nüve EC-160), $37^{\circ} \mathrm{C}$ 'de hücreler tam tabaka olana kadar büyütüldü. Büyütülen hücreler $\% 0,05$ Tripsin-EDTA (Sigma T-4049) yardımıyla kaldırılarak pasajlama işlemi gerçekleştirildi. Hücrelerin morfolojik değişiklikleri invert mikroskop (Olympus CK40) altında kontrol edildi.

\section{MTT Testi}

MTT (3-[4,5-Dimethylthiazole-2-yl]-2,5-diphenyltetrazolium bromide) ölçümü belirli bir hücre yoğunluğundaki canlı hücrelerin kolorimetrik yöntemle tespit edilmesidir. $\mathrm{Bu}$ yöntemin çalışma prensibi, hücrelerin sağlam mitokondrisi içerisinde bulunan süksinat dehidrogenaz enzimi etkisiyle MTT boyasının tetrazolium halkasının parçalanarak formazana dönüşmesi ilkesine dayanmaktadır (30). Hücreler 96 kuyucuklu hücre kültür platelerine ekilerek ZnONPs'nin farklı konsantrasyonlarıyla (1-1000 $\mu \mathrm{g} / \mathrm{mL})$ 24 saat, $\% 5 \mathrm{CO}_{2}{ }^{\prime} l i$ etüvde, $37^{\circ} \mathrm{C}$ 'de inkübe edildi. İnkübasyon sonrasında MTT hücre proliferasyon ölçüm kiti kullanılarak sitotoksisite testi yapıldı (Intron 21180, Kore). ZnONPs'nin farklı konsantrasyonlarıla inkübasyon tamamlandıktan sonra medyum atılarak $100 \mu \mathrm{L}$ taze medyum eklendi. Hücrelerin üzerine $10 \mu \mathrm{L}$ MTT stok solüsyonu $(5 \mathrm{mg} / \mathrm{mL})$ eklenerek $37^{\circ} \mathrm{C}^{\prime}$ de 4 saat inkübe edildi. İnkübasyon sonrasında $100 \mu \mathrm{L}$ solübilizasyon solüsyonu eklenerek $37^{\circ} \mathrm{C}$ 'de 4 saat inkübe edildi. Absorbans ölçümü $570 \mathrm{~nm}$ 'de Elisa okuyucu (Thermo Multiscan 1500, USA) kullanılarak gerçekleştirildi.

\section{BULGULAR}

\section{UV Analizi}

Nanopartikül sentezine $\mathrm{ZnSO}_{4}$ derişiminin etkisini belirlemek için, sabit enginar ekstraktına karşı $1 \mathrm{mM}$, $5 \mathrm{mM}, 7,5 \mathrm{mM}$ ve $10 \mathrm{mM} \mathrm{ZnSO}_{4}$ ile tepkime gerçekleştirilmiştir. Elde edilen UV-Vis spektrumuna bakıldığında 320-335 nm aralığında absorbans artışı gözlemlenmiştir (Şekil 2).

\section{FTIR Analizi}

$426 \mathrm{~cm}^{-1}$ ve $540 \mathrm{~cm}^{-1}$ ' deki bantlar ZnONPs'ye ait gerilme titreşimleridir. $3441 \mathrm{~cm}^{-1}$ 'deki geniş bant ise ZnONPs üzerindeki enginarın organik kalıntılarına ait $\mathrm{O}-\mathrm{H}$ gerilmesi ve $2887 \mathrm{~cm}^{-1}$ deki pik ise $\mathrm{C}-\mathrm{H}$ gerilme titreşimlerine aittir (Şekil 3). 


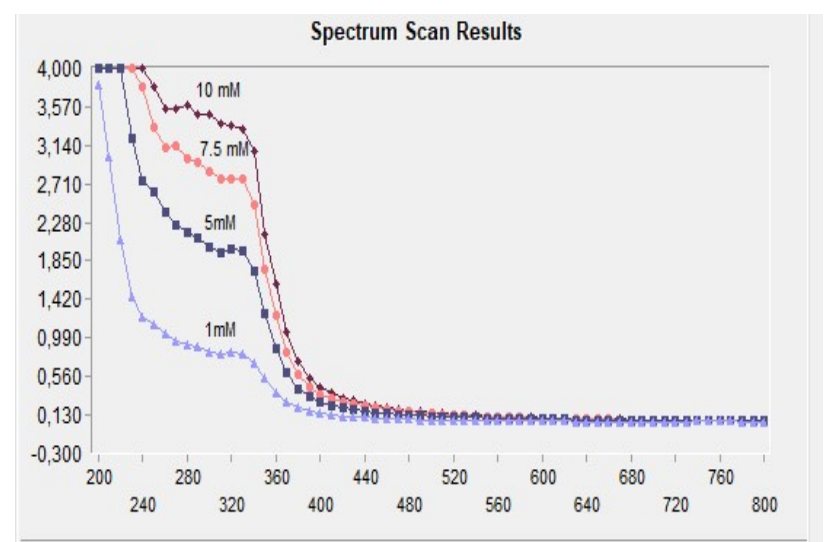

Şekil 2. Sentezlenen çinko nanopartiküllerine ait UV Spektrumu

\section{SEM ve EDX Analizi}

Taramalı elektron mikroskobu ile elektron bombardımanına tabi tutulan ZnONPs'nin daha dayanıklı ve küresel oldukları tespit edilmiştir (Şekil 4a). ZnONPs'nin parçacık boyutunun 276-309 nm aralığında olduğu görülmüştür. Ayrıca ZnONPs'nin birleşerek yaklaşık $2 \mu \mathrm{m}$ civarında küresel agregatlar oluşturduğu tespit edilmiştir. ZnONPs'nin EDX spektrumu çinko, karbon, fosfor, kükürt ve oksijen elementleri zirvelerini göstermektedir. \%2,32'lik çinko piki ZnONPs sentezini doğrulamaktadır (Şekil 4b).

\section{Zeta-sizer Analizi}

$\mathrm{Su}$ fazı içerisinde disperse ZnONPs'nin partikül büyüklüğü ölçümü için 5 tekrarlı 3 ölçüm gerçekleştirilmiştir. Partikül büyüklüğü için $173^{\circ}$ açı ve $25^{\circ} \mathrm{C}$ sıcaklık, zeta yükü için $12^{\circ}$ açı ve $25^{\circ} \mathrm{C}$ sicaklıkta ölçümler alınmıştır. ZnONPs için ortalama partikül büyüklüğü $137,8 \pm 36,49 \mathrm{~nm}$, polidispersite indeksi ise 0,03 ve zeta potansiyel yükleri $\mathrm{ZS}:-6,34+0,305 \mathrm{mV}$ olarak bulunmuştur.

\section{Antimikrobiyal Aktivite Sonuçları}

Agar kuyucuk difüzyon yönteminde enginar ekstraktıyla sentezlenen ZnONPs, E. coli ve $S$. aureus bakterilerine karş1 etki göstermiştir (Şekil 5). E. coli'nin $10 \mathrm{mg} / \mathrm{mL}$ 'de zon çap1 $8,0 \pm 0 \mathrm{~mm}, S$. aureus zon çap1 $8,0 \pm 0,1 \mathrm{~mm}$ bulunmuştur. ZnONPs, E. faecalis ve $P$. aeruginosa bakterilerine karşı etki göstermemiştir. ZnONPs'nin E. coli, S. aureus, $P$. aeruginosa, E. faecalis üzerine MIK değerleri $128 \mu \mathrm{g} / \mathrm{mL}$ 'nin üzerinde olduğu saptanmıştır.

\section{Sitotoksisite Sonuçları}

1-1000 $\mu \mathrm{g} / \mathrm{mL}$ konsantrasyonda ZnONPs'nin HT-29 insan kolon kanseri hücreleri üzerindeki sitotoksik etkileri MTT yöntemiyle ölçülmüştür. 0-24 saat yapılan inkübasyon sonrasında düşük konsantrasyonlarda hücre canlılığını sağladığı, \%50'den az hücre canlılı̆̆ının $10 \mu \mathrm{g} / \mathrm{mL}$ ZnONPs'de 24 saatte başladığı görülmektedir (Şekil 6a).

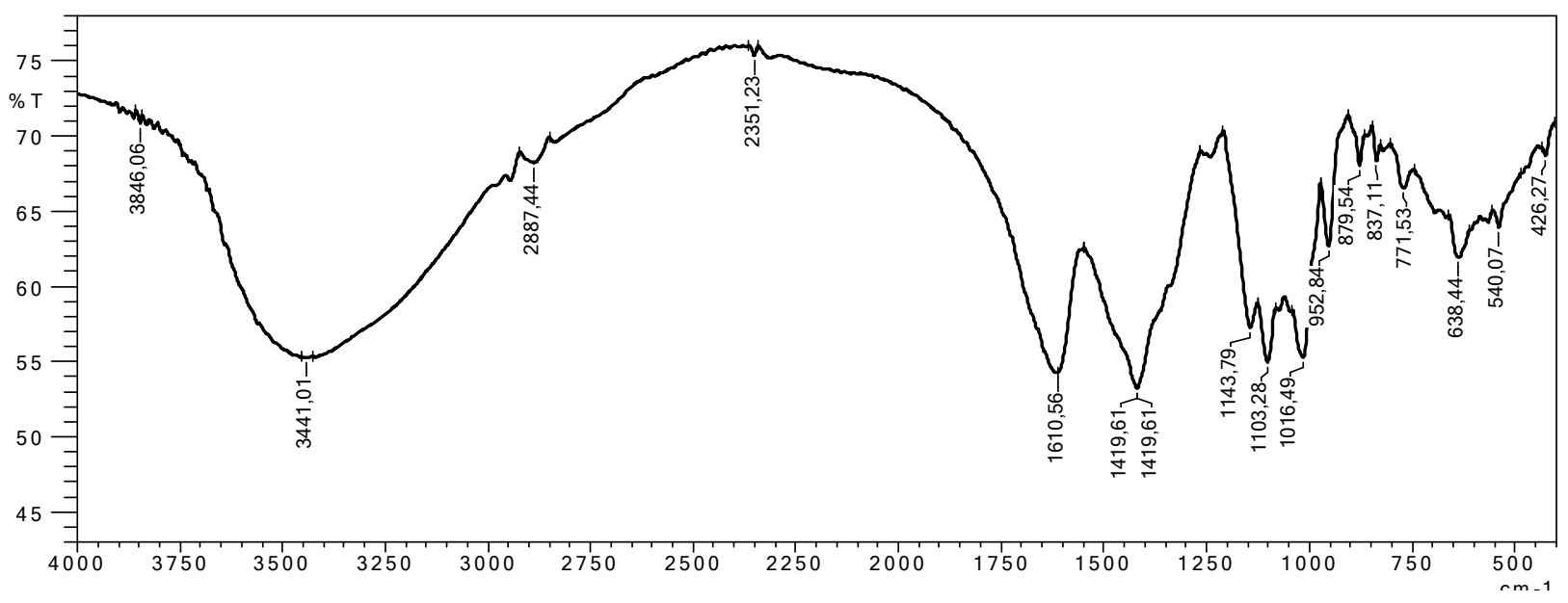

Şekil 3. Çinko oksit nanopartiküllerine ait FTIR spektrumu

a)

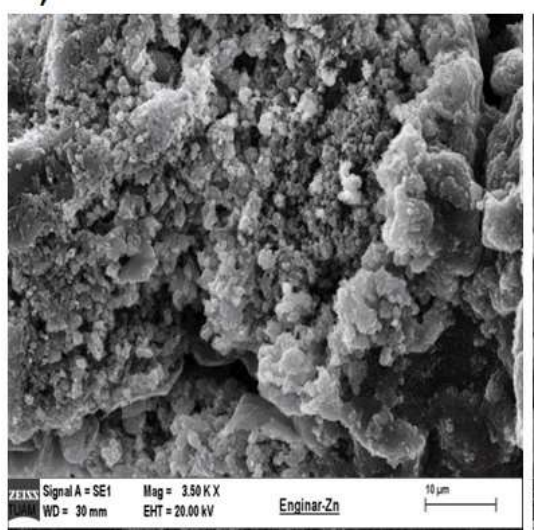

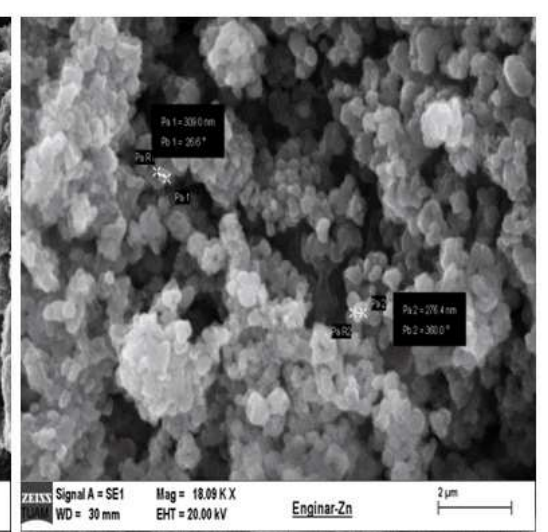

b)

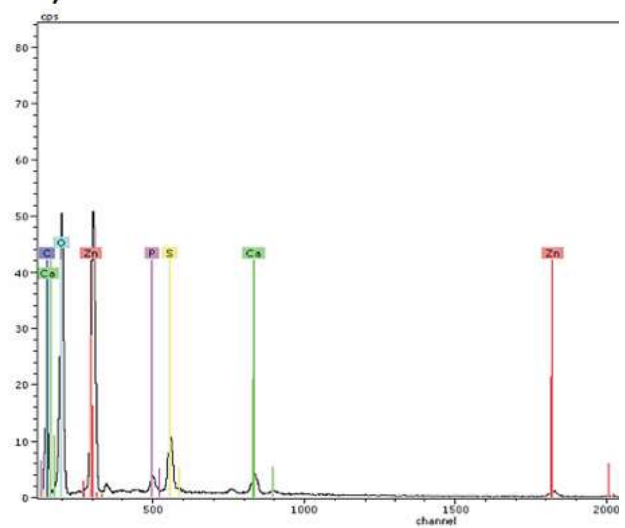

Şekil 4. ZnONPs'nin SEM görüntüsü (a) ve EDX spektrumu (b) 
E. faecalis

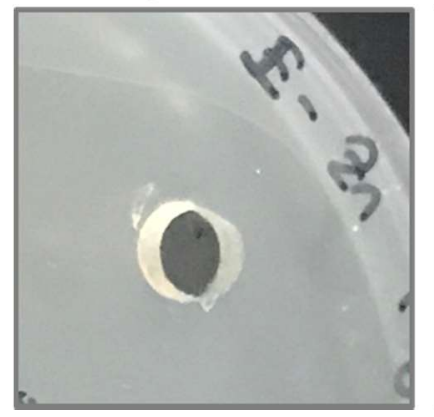

Şekil 5. ZnONPs'nin agar kuyucuk difüzyon yönteminde bakteriler üzerine etkisi

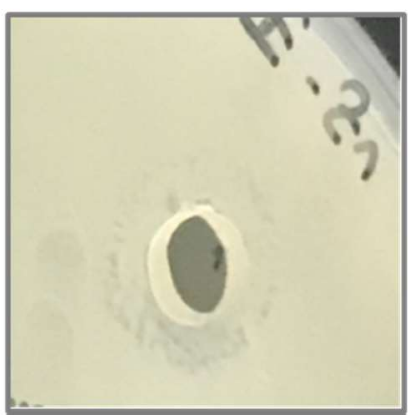

P. Aeruginosa

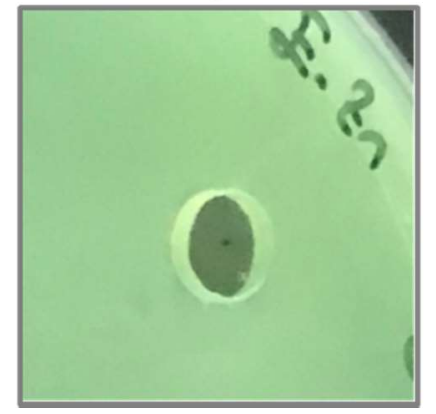

S. Aureus

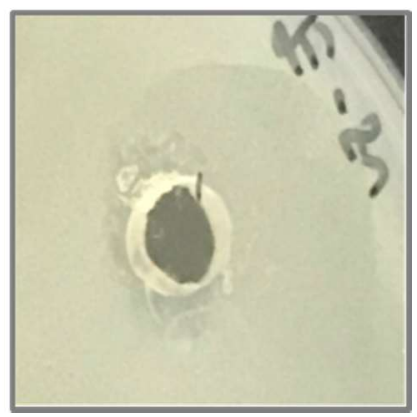

b)
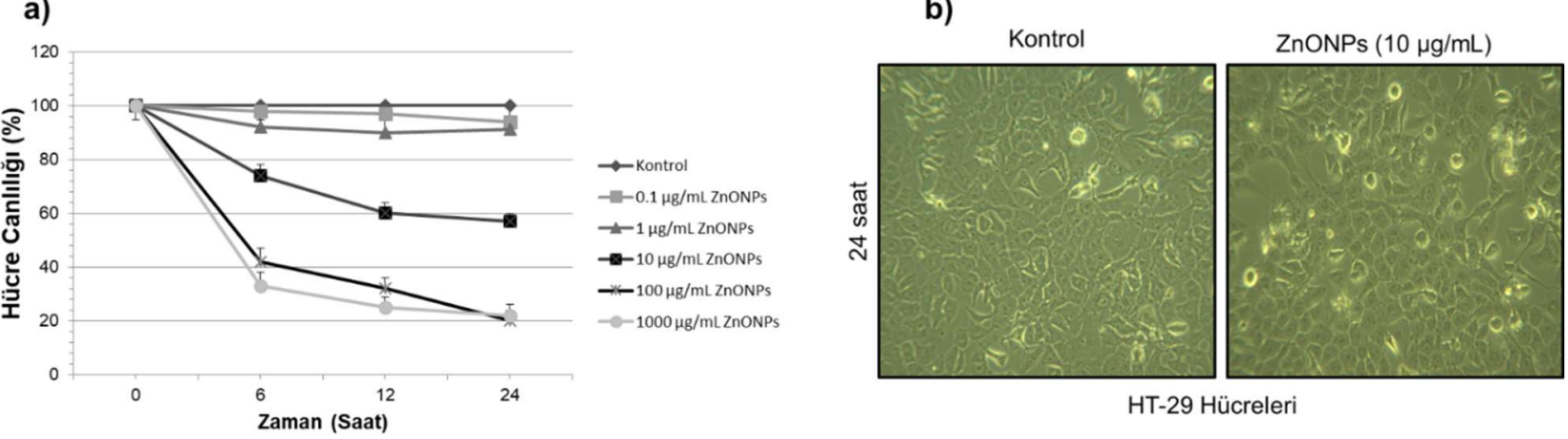

Şekil 6. ZnONPs'nin HT-29 hücrelerinde konsantrasyona bağlı hücre canlılığı (a) ve 24 saat inkübasyon sonrası hücre görüntüsü (b)

Bununla birlikte $10 \mu \mathrm{g} / \mathrm{mL}$ 'den daha yüksek konsantrasyonlarda 6 . saatten itibaren toksik etki göstererek hücre canlılığını azalttığı tespit edilmiştir. Aynı zamanda 24 saat sonrasi ZnONPs $10 \mu \mathrm{g} / \mathrm{mL}$ konsantrasyonda hücre morfolojilerindeki değişiklikler tespit edilmiştir (Şekil 6b). Hücre yapılarında birbirleri ile iletişimin azaldığı ve hücrelerin çekirdeklerinde DNA kondensasyonunun bozulduğu mikroskopla tespit edilmiştir.

\section{TARTIŞMA}

Bitki ekstraktları içerdikleri zengin biyoaktif bileşenlerden dolayı metal atomlarını oksitleyebildikleri için metal oksit nanopartiküllerinin sentezinde sıklıkla kullanılmaktadır. $\mathrm{Bu}$ biyoaktif bileşenler sentez aşamasında metal oksitlerinin yüzeyine de bağlanabilmekte ve metal oksitlerinin antibakteriyel ve antikanser özellik kazanmasını sağlamaktadır (31-35). Literatürde aloe barbadensis miller, Calotropis gigantean, Abrus precatorius, Aloe barbadensis, Cassia auriculata, Acalypha indica, Parthenium hysterophorus, Camellia sinensis, Calotropis procera, Musa balbisiana, Citrus paradise, Medicago sativa gibi farklı bitki ekstreleri kullanılarak yeşil kimya yoluyla ZnONPs sentezlendiği görülmektedir (36). Enginar yaprağı (Cynara scolymus) ekstraktının saponinler, kafeik asit türevleri, flavanoid türevleri, yağ asitleri ve çeşitli polifenolik bileşenler içerdiği bilinmektedir (37,38). Cynara scolymus kullanılarak gümüş nanopartiküllerinin yeşil kimya yoluyla sentezlendiği literatürde bildirilmiştir (24,39).
İçerdiği biyoaktif bileşenlerden dolayı enginar yaprağının sulu ekstraktı bu çalışmada ZnONPs'nin sentezinde kullanılmıştır. Kimyasal metotlarla senteze alternatif olarak, enginar yaprağı sulu ekstraktı ile ZnONPs'nin yeşil kimya yoluyla sentezi ilk defa bu çalışma ile gösterilmiştir. Yeşil kimya yoluyla sentezlenen ZnONPs'nin toksik kimyasallar içermemesi sebebiyle farmasötik ve tıbbı uygulamalar için kullanımının daha uygun olduğu ile ilgili görüşler mevcuttur (40).

ZnONPs'nin yapısı, UV-Vis, FTIR, SEM, TEM, EDX, Zeta sizer gibi çeşitli enstrümental yöntemlerle aydınlatılmaktadır. Bu çalışmada da UV-Vis, FTIR ve EDX dataları yeşil kimya sentezi ile enginar sulu ekstraktından ZnONPs oluşumunu desteklemektedir. Genellikle ZnONPs'nin $330 \mathrm{~nm}$ deki $\lambda$ max değerleri partiküllerin sentezlerinin gerçekleştirildiğini göstermektedir (41-43). Literatürle değerlendirildiği zaman bu çalışmada bulunan 320-335 nm arasındaki bant aralıkları ZnONPs sentezini desteklemektedir. FTIR sonuçlarında elde edilen $426 \mathrm{~cm}^{-1}$ ve $540 \mathrm{~cm}^{-1}$ 'deki bantların ZnONPs'ye ait gerilme titreşimleri olduğu görülmüştür. ZnONPs'nin yapısında, enginarın içerdiği organik kalıntılardan kaynaklanan $\mathrm{O}-\mathrm{H}$ gerilme titreşimleri $3441 \mathrm{~cm}^{-1}$, de ve $\mathrm{C}-\mathrm{H}$ gerilme titreşimleri ise $2887 \mathrm{~cm}^{-1}$ de tespit edilmiştir. Yine aromatik gruplara ait olan C-C gerilme titreşimleri $1419 \mathrm{~cm}^{-1}$ 'de görülmüştür (44-47). EDX spektrumunda görülen çinko pikinin $\mathrm{ZnO}$ sentezini desteklediği ve karbon, fosfor ve kükürte ait piklerin ise ZnONPs'nin yüzeyine tutunan biyoaktif bileşenlerden kaynaklandığı tespit edilmiştir $(13,45,48)$. 
ZnONPs'nin nanotıp uygulamalarda etkinliğinin fazla olması ve hücresel boyutta etkileşim yapabilmesi için boyut sınırı $\leq 200 \mathrm{~nm}$ olmas1 istenmektedir (49). Bu çalışmada SEM ve zeta sizer ölçümlerinde, sentezlenen nanopartiküllerin sulu ortamdaki partikül boyutunun nanotıp uygulamaları için istenen boyutlar içinde olduğu ve hücre içerisine girebilecek kapasitede yüke sahip olduğu gösterilmiştir. Ayrıca SEM çalışmalarında sentezlenen ZnONPs'nin dayanıklı ve küresel bir yap1 taşıması sebebiyle, ZnONPs'nin ilaç veya hedef molekül taşıyıcısı olarak gelecekte kullanılabileceği düşünülmektedir.

ZnONPs'nin C. jejeuni, S. enterica serovar Enteritidis, E coli, S. aureus, Vibrio cholerae gibi çeşitli bakterilerin büyümesini inhibe ettiği bilinmektedir (50). Bu çalışmada referans bakteri olarak; iki gram negatif bakteri (E. coli ATCC 25922 ve $P$. aeruginosa DSM 22644) ve iki gram pozitif bakteri (S. aureus ATCC 25923 ve E. faecalis JH2-2) kullanılmıştır. Sentezlenen ZnONPs'nin $S$. aureus ve $E$. coli'ye karşı göstermiş olduğu anti-bakteriyel etki, hem gram negatif hem de gram pozitif bakterilere karşı etkili olabileceğini göstermiş ve literatürle uyumludur (51). $P$. aeruginosa bakterisi biyofilm oluşturma özelliği olan patojen bir bakteridir ve yüzeylerde biyofilm oluşturarak kolonize olmaktadır. ZnONPs'nin $\quad 350 \mu \mathrm{g} / \mathrm{mL}$ 'lik konsantrasyonda $P$. aeruginosa'nın biyofilm oluşumunu inhibe ettiği gösterilmiştir (52). Antiseptiklerin içerisinde yer alan ZnONPs'nin ayrica kozmetikte kepek önleyici şampuanlarda, cilt döküntüleri için pomatlarda, yara iyileşmesi için mineralli kremlerde ve tıbbi bandajlar gibi pek çok ürünün içeriğinde yer aldığı da bildirilmektedir $(53,54)$. Bu sonuçlar işı̆̆ında, bu çalışmada sentezlenen ZnONPs'nin boyutunun küçüklüğü ve negatif yükü sebebiyle sabun, krem vb. anti-bakteriyel ürünlerin içeriğinde kullanılma potansiyeli bulunmaktadır.

Nanopartiküller kanser tedavisinde ilaçlar için taşıyıcı sistem geliştirme araştırmalarında yaygın olarak kullanılmaktadır. Bu konuda yeni sistemlerin geliştirilmesi ve hedeflenen moleküllerin ilgili kanser hücrelerine yönlenebilmesi konusunda nanopartiküller önemli avantajlar sunmaktadır. Bununla birlikte literatürde ZnONPs'nin çeşitli kanser hücre hatları üzerinde kemoterapötik etki gösterdiği bildirilmiştir (55-57). Yapılan araştırmalarda $\mathrm{C} 2 \mathrm{C} 12$ miyoblastoma kanser hücrelerinde (58), MCF-7 meme kanser hücrelerinde (59), HepG2 hepatoselüler kanser hücrelerinde (56), Caco-2 kolon kanser hücrelerinde (60), SKOV3 over kanser hücrelerinde (61), Hela servikal kanser hücrelerinde (62), tek başlarına veya bir ilaç taşıyıcı sistem olarak apoptozu indüklediği ve kanser hücrelerinin proliferasyonu azalttığ 1 bildirilmiştir. Ayrıca ZnONPs'nin anti kanser etkilerinin temelinde, hücre içerisine giren çözünmüş çinko iyonlarının konsantrasyonunun artışına bağlı olarak reaktif oksijen türlerinin meydana geldiği ve bu olayın hücre içerisinde apoptotik sinyal yolaklarını harekete geçirdiği düşünülmektedir (63). Boyutlarının küçüklüğü sebebiyle hem ilaç taşımada hem de terapötik etkiler göstermeleri sebebiyle ilgi duyulan bu ZnONPs konusunda son yillarda araştırmalar hızla artmaktadır. Bu çalışmada sentezlenen ZnONPs'nin HT-29 insan kolon kanseri hücreleri üzerinde doza ve zamana bağlı olarak anti-kanser etki gösterdiği ve sahip olduğu negatif yük nedeniyle hücre içerisine girebilecek boyutta olduğu görülmüştür. $\mathrm{Bu}$ etkilerinden dolayı ZnONPS kolon kanseri tedavisinde yeni terapötiklerin geliştirilmesine katkıda bulunabilir.

\section{SONUÇ}

Sonuç olarak enginar ekstraktı kullanılarak yeşil kimya yoluyla sentezlenen ZnONPs anti-bakteriyel ve antikanser etkileri sebebiyle yeni ilaç taşıyıcı sistemler için hedef molekül olabilir.

\section{KAYNAKLAR}

1. Santhoskumar J, Venkat Kumar S, Rajeshkumar S. Synthesis of zinc oxide nanoparticles using plant leaf extract against urinary tract infection pathogen. Resource-Efficient Technologies. 2017;3(4):459-65.

2. Sutradhar P, Saha M. Green synthesis of zinc oxide nanoparticles using tomato (Lycopersicon esculentum) extract and its photovoltaic application. J Exp Nanosci. 2016;11(5):314-27.

3. Khan ST, Musarrat J, Al-Khedhairy AA. Countering drug resistance, infectious diseases, and sepsis using metal and metal oxides nanoparticles: current status. Colloids Surf B Biointerfaces. 2016;146:70-83.

4. Chen J, Liu X, Wang C, Yin SS, Li XL, Hu WJ, et al. Nitric oxide ameliorates zinc oxide nanoparticlesinduced phytotoxicity in rice seedlings. J Hazard Mater. 2016;297:173-82.

5. Nair S, Sasidharan A, Divya Rani VV, Menon D, Nair $\mathrm{S}$, Manzoor $\mathrm{K}$, et al. Role of size scale of $\mathrm{ZnO}$ nanoparticles and microparticles on toxicity toward bacteria and osteoblast cancer cells. J Mater Sci Mater Med. 2009;20(Suppl 1):235-41.

6. Hanley C, Layne J, Punnoose A, Reddy KM, Coombs I, Coombs A, et al. Perferential killing of cancer cells anda activated human $\mathrm{T}$ cells using $\mathrm{ZnO}$ nanoparticles. Nanotecnology. 2008;19(29):295103.

7. Premanathan M, Karthikeyan K, Jeyasubramanian K, Manivannan G. Selective toxicity of $\mathrm{ZnO}$ nanoparticles toward Gram-positive bacteria and cancer cells by apoptosis through lipid peroxidation. Nanomedicine. 2011;7(2):184-92.

8. Aksoy B, Atakan N, Aksoy HM, Tezel GG, Renda N, Ozkara HA, et al. Effectiveness of topical zinc oxide application on hypertrophic scar development in rabbits. Burns. 2010;36(7):1027-35.

9. Shokri N, Javar HA. Comparison of calcium phosphate and zinc oxide nanoparticles as dermal penetration enhancers for albumin. Indian $\mathrm{J}$ Pharm Sci. 2015;77(6):694-704.

10. Sahdev P, Podaralla S, Kaushik RS, Perumal O. Calcium phosphate nanoparticles fortranscutaneous vaccine delivery. J Biomed Nanotechnol. 2013;9(1):132-41.

11. Parveen K, Banse V, Ledwani L. Green synthesis of nanoparticles: their advantages and disadvantages. AIP Conf Proc. 2016;1724(1):020048.

12. Agarval H, Venkat Kumar S, Rajeshkumar S. A review on green synthesis of zinc oxide nanoparticles - An eco-friendly approach. Resource-Efficient Tecnologies. 2017;3(4):406-13.

13. Abdul Salam H, Sivaraj R, Venckatesh R. Green synthesis and characterization of zinc oxide nanoparticles from Ocimum basilicum L. var. 
purpurascens Benth.-lamiaceae leaf extract. Mater Lett. 2014;131:16-18.

14. Rajendran SP, Sengodan K. Synthesis and characterization of zinc oxide and iron oxide nanoparticles using Sesbania grandiflora leaf extract as reducing agent. Journal of Nanoscience. 2017;2017:8348507.

15. Yuvakkumar R, Suresh J, Nathanael AJ, Sundrarajan $\mathrm{M}$, Hong SI. Novel green synthetic strategy to prepare $\mathrm{ZnO}$ nanocrystals using rambutan (Nephelium lappaceum L.) peel extract and its antibacterial applications. Mater Sci Eng C Mater Biol Appl. 2014;41:17-27.

16. Pereira C, Calhelha RC, Barros L, Ferreira ICFR. Antioxidant properties, anti-hepatocellular carcinoma activity and hepatotoxicity of artichoke, milk thistle and borututu. Ind Crops Prod. 2013;49:61-5.

17. Nassar MI, Mohamed TK, Elshamy AI, El-Toumy SA, Abdel Lateef AM, Farrag ARH. Chemical constituents and anti-ulcerogenic potential of the scales of Cynara scolymus (artichoke) heads. J Sci Food Agric. 2013;93(10):2494-501.

18. Seelinger G, Merfort I, Schempp CM. Anti-oxidant, anti-inflammatory and anti-allergic activities of luteolin. Planta Med. 2008;74(14):1667-77.

19. Machado I, Cesio MV, Dol I, Piston M. A Rapid sample preparation method for the determination of cadmium and lead in spinach and artichoke leaves using ozone. American Journal of Food Science and Technology. 2015;3(3):55-9.

20. Tang X, Wei R, Deng A, Lei T. Protective effects of ethanolic extracts from artichoke, an edible herbal medicine, against acute alcohol-1nduced liver injury in mice. Nutrients. 2017;9(9):1000.

21. Wittemer SM, Ploch M, Windeck T, Müller SC, Drewelow B, Derendorf $\mathrm{H}$, et al. Bioavailability and pharmacokinetics of caffeoylquinic acids and flavonoids after oral administration of artichoke leaf extracts in humans. Phytomedicine. 2005;12(1-2):28-38.

22. Machado I, Dol I, Rodríguez-Arce E, Cesio MV, Piston M. Comparison of different sample treatments for the determination of $\mathrm{As}, \mathrm{Cd}, \mathrm{Cu}, \mathrm{Ni}, \mathrm{Pb}$ and $\mathrm{Zn}$ in globe artichoke (Cynara cardunculus L. subsp. Cardunculus). Microchem J. 2016;128:128-33.

23. Lombardo S, Pandino G, Mauromicale G. Minerals profile of two globe artichoke cultivars as affected by NPK fertilizer regimes. Food Res Int. 2017;100(Pt 2):95-9.

24. Sampaio S, Viana JC. Production of silver nanoparticles by green synthesis using artichoke (Cynara scolymus L.) aqueous extract and measurement of their electrical conductivity. Adv Nat Sci-Nanosci. 2018;9:045002.

25. Rao KG, Ashok CH, Rao KV, Chakra CHS, Akshaykranth A. Eco-friendly synthesis of $\mathrm{MgO}$ nanoparticles from orange fruit waste. Int J Appl Phys Sci. 2015;2(3):1-6.

26. Joseph S, Mathew B. Microwave-assisted green synthesis of silver nanoparticles and the study on catalytic activity in the degradation of dyes. J Mol Liq. 2015;204:184-91.

27. Haris M, Kumar A, Ahmad A, Abuzinadah F, Basheikh M, Khan SA, et al. Microwave-assisted green synthesis and antimicrobial activity of silver nanoparticles derived from a supercritical carbon dioxide extract of the fresh aerial parts of Phyllanthus niruri L. Trop J Pharm Res. 2017;16(12):2967-76.

28. Jahangirian $\mathrm{H}$, Haron MJ, Ismail MHS, RafieeMoghaddam R, Afsah-Hejri L, Abdollahi Y, et al. Well diffusion method for evaluation of antibacterial activity of copper phenyl fatty hydroxamate synthesized from canola and palm kernel oils. Dig J Nanomater Bios. 2013;8(3):1263-70.

29. Al-Bayati FA, Sulaiman KD. In vitro antimicrobial activity of salvadora persica 1 . extracts against some isolated oral pathogens in Iraq. Turk $\mathrm{J}$ Biol. 2008;32(1):57-62.

30. Baek SH, Kim YO, Kwag JS, Choi KE, Jung WY, Han DS. Boron trifluoride etherate on silica-A modified Lewis acid reagent (VII). Antitumor activity of cannabigerol against human oral epitheloid carcinoma cells. Arch Pharm Res. 1998;21(3):353-6.

31. Lu W, Qin X, Liu S, Chang G, Zhang Y, Luo Y, et al. Economical, green synthesis of fluorescent carbon nanoparticles and their use as probes for sensitive and selective detection of mercury(II) ions. Anal Chem. 2012;84(12):5351-7.

32. Bar H, Bhui DK, Sahoo GP, Sarkar P, Pyne S, Misra A. Green synthesis of silver nanoparticles using seed extract of Jatropha curcas. Colloids Surf A Physicochem Eng Asp. 2009;348(1-3):212-6.

33. Sangeetha G, Rajeshwari S, Venckatesh R. Green synthesis of zinc oxide nanoparticles by aloe barbadensis miller leaf extract: Structure and optical properties. Mater Res Bull. 2011;46(12):2560-6.

34. Ramesh M, Anbuvannan M, Viruthagari G. Green synthesis of $\mathrm{ZnO}$ nanoparticles using Solanum nigrum leaf extract and their antibacterial activity. Spectrochim Acta A Mol Biomol Spectrosc. 2015;136(Pt B):864-70.

35. Khatami M, Varma RS, Zafarnia N, Yaghoobi $H$, Sarani M, Kumar VG. Applications of green synthesized $\mathrm{Ag}, \mathrm{ZnO}$ and $\mathrm{Ag} / \mathrm{ZnO}$ nanoparticles for making clinical. Sustainable Chem Pharm. 2018;10:915.

36. Mirzaei H, Darroudi M. Zinc oxide nanoparticles: Biological synthesis and biomedical applications. Ceram Int. 2017;43(1):907-14.

37. Farag MA, El-Ahmady SH, Elian FS, Wessjohann LA. Metabolomics driven analysis of artichoke leaf and its commercial products via UHPLC-q-TOF-MS and chemometrics. Phytochemistry. 2013;95:177-87.

38. Wang M, Simon JE, Aviles IF, He K, Zheng QY, Tadmor Y. Analysis of antioxidative phenolic compounds in artichoke (Cynara scolymus L.). J Agric Food Chem. 2003;51(3):601-8.

39. Erci F, Cakir-Koc R, Isildak I. Green synthesis of silver nanoparticles using thymbra spicata L. var. spicata (zahter) aqueous leaf extract and evaluation of their morphology-dependent antibacterial and cytotoxic activity. Artif Cells Nanomed Biotechnol. 2018;46(sup1):150-8.

40. Mishra PK, Mishra H, Ekielski A, Talegaonkar S, Vaidya B. Zinc oxide nanoparticles: a promising nanomaterial for biomedical applications. Drug Discov Today. 2017;22(12):1825-34. 
41. Varghese E, George M. Green synthesis of zinc oxide nanoparticles. International Journal of Advance Research in Science and Engineering. 2015;4(1):30714.

42. Chung IM, Rahuman AA, Marimuthu S, Kirthi AV, Anbarasan K, Rajakumar G. An investigation of the cytotoxicity and caspase-mediated apoptotic effect of green synthesized zinc oxide nanoparticles using eclipta prostrata on human liver carcinoma cells. Nanomaterials (Basel). 2015;5(3):1317-30.

43. Yedurkar S, Maurya C, Mahanwar P. Biosynthesis of zinc oxide nanoparticles using ixora coccinea leaf extract-A green approach. Journal of Synthesis Theory and Applications. 2016;5(1):1-14.

44. Aminüzzaman M, Ying LP, Goh WS, Watanebe A. Green synthesis of zinc oxide nanoparticles using aqueous extract of Garcinia mangostana fruit pericarp and their photocatalytic activity. Bull Mater Sci. 2018;41(2):50.

45. Elumalai K, Velmurugan S. Green synthesis, characterization and antimicrobial activities of zinc oxide nanoparticles from the leaf extract of Azadirachta indica (L.). Appl Surf Sci. 2015;345:329-36.

46. Gnanasangeetha D, Sarala Thambavani D. One pot synthesis of zinc oxide nanoparticles via chemical and green method. Res J Material Sci. 2013;1(7):1-8.

47. Xiong HM, Shchukin DG, Möhwald H, Xu Y, Xia YY. Sonochemical synthesis of highly luminescent zinc oxide nanoparticles doped with magnesium (II). Angew Chem Int Ed. 2009;48(15):2727-31.

48. Selvarajan E, Mohanasrinivasan V. Biosynthesis and characterization of $\mathrm{ZnO}$ nanoparticles using Lactobacillus plantarum VITES07. Mater Lett. 2013;112:180-2.

49. Rizvi SAA, Saleh AM. Applications of nanoparticle systems in drug delivery technology. Saudi Pharm J. 2018;26(1):64-70.

50. Sirelkhatim A, Mahmud S, Seeni A, Kaus NHM, Ann LC, Bakhori SKM, et al. Review on zinc oxide nanoparticles: Antibacterial activity and toxicity mechanism. Nanomicro Lett. 2015;7(3):219-42.

51. Karvani ZE, Chehrazi P. Antibacterial activity of $\mathrm{ZnO}$ nanoparticle on gram-positive and gram-negative bacteria. Afr J Microbiol Res. 2011;5(12):1368-73.

52. Sangani MH, Moghaddam MN, Forghanifard MM. Inhibitory effect of zinc oxide nanoparticles on pseudomonas aeruginosa biofilm formation. Nanomed J. 2015;2(2):121-28.

53. Kuo CL, Wang CL, Ko HH, Hwang WS, Chang KM, $\mathrm{Li}$ WL, et al. Synthesis of zinc oxide nanocrystalline powders for cosmetic applications. Ceram Int. 2010;36(2):693-8.

54. Dao DV, van den Bremt M, Koeller Z, Le TK. Effect of metal ion doping on the optical properties and the deactivation of photocatalytic activity of $\mathrm{ZnO}$ nanopowder for application in sunscreens. Powder Technol. 2016;288:366-70.

55. Holohan C, Van Schaeybroeck S, Longley DB, Johnston PG. Cancer drug resistance: an evolving paradigm. Nat Rev Cancer. 2013;13(10):714-26.

56. Akhtar MJ, Ahamed M, Kumar S, Khan MM, Ahmad J, Alrokayan SA. Zinc oxide nanoparticles selectively induce apoptosis in human cancer cells through reactive oxygen species. Int $\mathrm{J}$ Nanomedicine. 2012;7:845-57.

57. Priyadharshini RI, Prasannaraj G, Geetha N, Venkatachalam P. Microwave-mediated extracellular synthesis of metallic silver and zinc oxide nanoparticles using macro-algae (gracilaria edulis) extracts and its anticancer activity against human PC3 cell lines. Appl Biochem Biotechnol. 2014;174(8):2777-90.

58. Chandrasekaran $M$, Pandurangan $M$. In vitro selective anti-proliferative effect of zinc oxide nanoparticles against co-cultured $\mathrm{C} 2 \mathrm{C} 12$ myoblastoma cancer and 3T3-L1 normal cells. Biol Trace Elem Res. 2016;172(1):148-54.

59. Boroumand Moghaddam AB, Moniri M, Azizi S, Abdul Rahim R, Bin Ariff A, Navaderi M, et al. Ecofriendly formulated zinc oxide nanoparticles: induction of cell cycle arrest and apoptosis in the MCF-7 cancer cell line. Genes (Basel). 2017;8(10):281.

60. Fang X, Jiang L, Gong Y, Li J, Liu L, Cao Y. The presence of oleate stabilized $\mathrm{ZnO}$ nanoparticles (NPs) and reduced the toxicity of aged NPs to Caco-2 and HepG2 cells. Chem Biol Interact. 2017;278:40-7.

61. Bai DP, Zhang XF, Zhang GL, Huang YF, Gurunathan S. Zinc oxide nanoparticles induce apoptosis and autophagy in human ovarian cancer cells. Int $\mathbf{J}$ Nanomedicine. 2017;12:6521-35.

62. Hariharan R, Senthilkumar S, Suganthi A, Rajarajan M. Synthesis and characterization of doxorubicin modified $\mathrm{ZnO} / \mathrm{PEG}$ nanomaterials and its photodynamic action. $\mathrm{J}$ Photochem Photobiol B. 2012;116:56-65.

63. Sharma V, Anderson D, Dhawan A. Zinc oxide nanoparticles induce oxidative DNA damage and ROS-triggered mitochondria mediated apoptosis in human liver cells (HepG2). Apoptosis. 2012;17(8):852-70. 